\title{
The Role of Forth Generation (4G) Technology in the Reform of Rural India
}

\author{
Uttam Kumar \\ Research Scholar, Department of Management Studies, DR K N Modi University, Newai, Tonk, Rajasthan, India
}

\begin{abstract}
Forth Generation(4G) Technology can play an important role in significantly improving the quality, access and efficacy of healthcare, Education, Governance and in the Economic reforms of rural India. Reliable and fast internet is still a dream in the rural India. Usage of $4 \mathrm{~g}$ technology in is still in initial stage and many operators in India are in the early stage of deployment. $4 \mathrm{~g}$ has enormous potential as a technology to increase better and reliable internet connectivity to empower rural citizens by improving the health and well being of poor and marginalized populations, and encouraging sustainable development and governance. $4 G$ can play an important role in the Digital India Vision of the Government of India.
\end{abstract}

Keywords: 4G, rural reform, telemedicine, Digital India, IOT, Digital India, 4G telecom operators

\section{Introduction}

Broadband is an enabler in the macroeconomic growth of any country. According to World Bank analysis of 120 countries, $\rightarrow$ fr every 10 percentage point increase in the penetration of broadband services, there is an increase in the economic growth of 1.3 percentage points." The growth effect of broadband is stronger and significant in developing countries like India than developed countries and is higher than that of telephony and Internet. As a result, broadband technologies like $4 \mathrm{G}$ need to be encouraged by the Government to increase the penetration of broadband.

The market is changing and technology is playing an important role in the transformation. In order to transform the entire ecosystem of public services through the use of information technology, the government of India has approved the Đigital India - Programme with the vision to transform India into a digitally empowered society and knowledge economy. Governments and Health Management organizations are placing greater emphasis, and greater resources, on technology as an improvement tool.

The adoption of technological evolutions and adoption in the healthcare, e-governance, education, financial inclusion, Safety \& Security, Smart City Initiatives etc faces a number of obstacles due to non availability of good and reliable internet bandwidth. Reliable and fast internet is still a dream in the rural India.

$4 \mathrm{G}$ as a technology is very powerful and will be capable of providing between $100 \mathrm{Mbit} / \mathrm{s}$ and $1 \mathrm{Gbit} / \mathrm{s}$ speeds both indoors and outdoors, with premium quality and high security. Government of India has already awarded BWA(4G) license and

National Telecom Policy- 2012 talks about including broadband connectivity as a basic necessity like education and health and work towards 'Right to Broadband' and puts emphasis on providing reliable and affordable broadband access to rural and remote areas by appropriate combination of optical fibre, wireless, VSAT and other technologies.
In India, Internet Services were launched on 15th August 1995 by Videsh Sanchar Nigam Limited (VSNL). In November 1998 the Government opened the sector to Private Operators for provisioning of Internet Services. More than $95 \%$ subscribers were using dialup access at that time. In a bid to encourage high speed Internet growth in the country and to address the demand of application requiring more bandwidth, TRAI came up with its consultation on - Acelerating Growth of Internet and Broadband Penetration" in November 2003 and submitted its recommendations to DoT on 29th April 2004. Department of Telecom issued Broadband Policy thereafter.

Last two decades have witnessed a rapid growth in the number of mobile subscribers and equally rapid advancement in the mobile technology. With ever increasing demand for wireless multimedia applications requiring more and more bandwidth, radio access technologies are continuously evolving to provide higher data rates and improved spectral efficiency. As third generation (3G) International Mobile Telecommunication 2000 (IMT- 2000) systems are being deployed, evolution of further advanced systems, known as IMT-Advanced Systems is taking place. International Mobile Telecommunications-Advanced (IMTAdvanced) systems are mobile systems that include the new capabilities of IMT that go beyond those of IMT-2000. Such systems provide access to a wide range of telecommunication services including advanced mobile services, supported by mobile and fixed networks, which are increasingly packet-based. In order to facilitate introduction of IMT Advanced mobile broadband services, the Authority has decided to deliberate on various related issues including suitable spectrum bands, block size of spectrum to be auctioned, maximum spectrum permitted to bidder, eligibility criteria for bidding, rollout obligations, spectrum usage charges, QoS parameters, security issues and other related issues.

Since the inception of mobile communications in the early 1980s, there has been ever-growing increase in the development of mobile communication technology. Analog wireless communication systems have been replaced by digital ones, voice services are being complemented with data services, supported data transfer speeds have increased 


\section{International Journal of Science and Research (IJSR) \\ ISSN (Online): 2319-7064}

Index Copernicus Value (2013): 6.14 | Impact Factor (2014): 5.611

by more than a thousand-fold, network coverage has been stretched to cover virtually entire countries and continents, and many other remarkable achievements have taken place in a relatively short period.

Over $55 \%$ of children in India suffer from malnutrition, close to 10 million children don't go to school forget getting quality education, over 300 million people in India have no access to electricity, over 600 million people in India have no access to clean drinking water, toilets or good sanitation services - there is no dearth of statistics to show why rural India is so backward. Many such people from among the rural population are forced to move to urban areas in search of better opportunities that meet their aspirations, quality education for their children being one of the key drivers. The problems emerging out of this phenomenon have been many - families either uprooted from native cultures or separated from one another; lack of life skills to adapt to an alien urban environment leading to lost opportunities; unstructured and uncontrolled growth in urban areas leading to social and environmental tensions and more.

India is one of the leading countries focusing into EGovernance \& Digital India. The Indian government has now set up the target of delivering vast majority of services electronically. In this regard the Indian government major policy measures have been defined in computer density, connectivity content, cost and cyber laws. The Indian government has decided to boost computer connectivity by improving the roll out of broadband networks.

Electronic governance or E-Governance is the latest buzzword for governments trying to involve people in administration, address transparency in the bureaucracies and make themselves more responsive to their citizens. The benefits of E-Governance are faster decision making, reduction of duplication of work, detection of corruption and illegal transaction, prevention of knowledge drain.

E-governance is the most important discussion in the development agenda of almost all governments in the world and lot of money is being pumped to various eGovernance initiatives. India is also not left behind specifically with the rollout of good telecom and mobile infrastructure the back bone has already been created.

In the recent past India has also auctioned $3 \mathrm{~g} \& 4 \mathrm{~g}$ airwaves and county has seen $50-60 \%$ in the $3 \mathrm{~g}$ usage in the last one year. All Major telecom operators are also deploying $4 \mathrm{~g}$ technology both for consumes (B2C) and for the business (B2B).

\section{Forth Generation (4G) Technology}

There is no formal definition for what $4 \mathrm{G}$ is. However, there are certain objectives that are projected for $4 \mathrm{G}$ by ITU. The
International

Telecommunications

Union-Radio communications sector (ITU-R) specified a set of requirements for $4 \mathrm{G}$ standards, called as -International Mobile Telecommunications Advanced (IMT-Advanced)" specification, setting its peak speed requirements for $4 \mathrm{G}$ service at 100 megabits per second $(\mathrm{mb} / \mathrm{s})$ for high mobility communication and 1 gigabit per second ( $\mathrm{gb} / \mathrm{s}$ ) for low mobility communication. The first-release versions of Mobile WiMAX and LTE support much less than $1 \mathrm{~Gb} / \mathrm{s}$ peak bit rate, they were not fully IMT-A compliant, but were often branded $4 \mathrm{G}$ by Telecom Operators. ITU at a later stage recognized that these two technologies, as well as other beyond-3G technologies that do not fulfill the IMTAdvanced requirements, could nevertheless be considered "4G", provided they represent forerunners to be IMTAdvanced compliant versions and "a substantial level of improvement in performance and capabilities with respect to the initial third generation systems now deployed".

4G system does not support traditional circuit-switched telephony service, but it's a complete Internet Protocol (IP) based communication such as IP telephony.

The term $4 \mathrm{G}$ is used broadly to include several types of broadband wireless access communication systems, not only cellular telephone systems. While neither standard bodies nor carriers have concretely defined or agreed upon what exactly $4 \mathrm{G}$ will be fourth generation networks are likely to use a combination of WiMAX and Wi-Fi technologies. With $4 \mathrm{G}$, a range of new services and models will be available. These services and models need to be further examined for their interface with the design of $4 \mathrm{G}$.

There are few objectives for 4G:

- That $4 \mathrm{G}$ will be a fully IP-based integrated system.

- 4G will be capable of providing between $100 \mathrm{Mbit} / \mathrm{s}$ and 1 Gbit/s speeds both indoors and outdoors, with premium quality and high security.

\begin{tabular}{|l|l|l|l|l|l|}
\hline & $\begin{array}{l}\text { WCDMA } \\
\text { (UMTS) }\end{array}$ & HDPA & HSPA+ & LTE & $\begin{array}{l}\text { LTE } \\
\text { Advanced }\end{array}$ \\
\hline Max downlink speed( bps) & $384 \mathrm{k}$ & $14 \mathrm{M}$ & $28 \mathrm{M}$ & $300 \mathrm{M}$ & $1 \mathrm{G}$ \\
\hline Max uplink speed (bps) & $128 \mathrm{k}$ & $5.7 \mathrm{M}$ & $11 \mathrm{M}$ & $75 \mathrm{M}$ & $500 \mathrm{M}$ \\
\hline $\begin{array}{l}\text { Latency round trip time } \\
\text { (approx) }\end{array}$ & $150 \mathrm{~ms}$ & $100 \mathrm{~ms}$ & $\begin{array}{l}50 \mathrm{~ms} \\
(\max )\end{array}$ & $\sim 10 \mathrm{~ms}$ & $\begin{array}{l}\text { less than } \\
5 \mathrm{~ms}\end{array}$ \\
\hline 3GPP releases & Rel 99/4 & Rel $5 / 6$ & Rel 7 & Rel 8 & Rel 10 \\
\hline $\begin{array}{l}\text { Approx years of initial roll } \\
\text { out }\end{array}$ & $2003 / 4$ & $\begin{array}{l}2005 / 6 \\
\text { HSDPA } \\
2007 / 8 \\
\text { HSUPA }\end{array}$ & $2008 / 9$ & $2009 / 10$ & \\
\hline Access methodology & CDMA & $\begin{array}{l}\text { CDMA } \\
\text { CDMA }\end{array}$ & $\begin{array}{l}\text { OFDMA } \\
\text { /SC- } \\
\text { FDMA }\end{array}$ & $\begin{array}{l}\text { OFDMA / } \\
\text { SC-FDMA }\end{array}$ \\
\hline
\end{tabular}

Figure 1: Comparison of Technolog 
International Journal of Science and Research (IJSR)

ISSN (Online): 2319-7064

Index Copernicus Value (2013): 6.14 | Impact Factor (2014): 5.611

\section{COMPARISON OF 1G, 2G, 3G, 4G, 5G}

\section{COMTPARUSOS OF ALL GENERATIOSS OF MOBILE TECHSOLOCIDS [1G-5G]}

\begin{tabular}{|c|c|c|c|c|c|c|c|}
\hline Generation & 10 & 20 & 2.50 & 30 & 3.50 & 40 & 56 \\
\hline Start & 2701980 & $1960-2000$ & 20012004 & 20042005 & 2006.2010 & 20t15s & Soen 0020 \\
\hline $\begin{array}{c}\text { Data } \\
\text { Bastriftet }\end{array}$ & 2 Elph & ABps & 166 iges & 2 Mps & $\begin{array}{l}\text { Wort twe } \\
2 \text { Mspe }\end{array}$ & 100 & nor the 1 Obor \\
\hline Teckaplog & Roling & $\begin{array}{l}\text { Dipal } \\
\text { Colles }\end{array}$ & 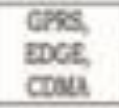 & 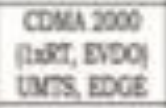 & $\begin{array}{l}\text { EDCE } \\
\text { wh }\end{array}$ & $\begin{array}{c}\text { Whar the } \\
\text { Wh }\end{array}$ & wow \\
\hline Service & Viser & 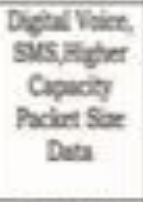 & $\begin{array}{l}\text { sys, } \\
\text { yeses }\end{array}$ & 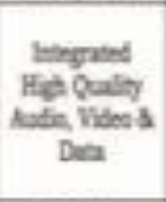 & 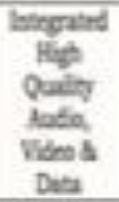 & 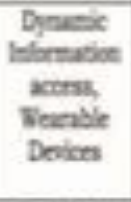 & 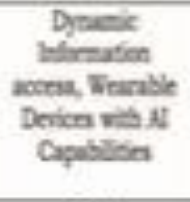 \\
\hline Waltiplexing & FDEA & $\begin{array}{l}\text { IDXA } \\
\text { cosea }\end{array}$ & cones & cosara & CDNa & $\cos a$ & $\cos a$ \\
\hline Switehisy & Cente & $\begin{array}{l}\text { Crovel } \\
\text { fact }\end{array}$ & Pachert & Padert & Rinciat & Afrid & As factert \\
\hline Cece Setwark & PSIX & PST & PSTIX & Pacen $5 / x$ & Intrat & Eternat & Eernat \\
\hline Fiadolf & Hortantal & Firaned & Horants & Horiantel & Rorisend & $\begin{array}{c}\text { Horiantal a } \\
\text { Bnted }\end{array}$ & $\begin{array}{c}\text { Horiantals } \\
\text { Virtical }\end{array}$ \\
\hline
\end{tabular}

Figure 2: Comparison of Technology

$4 \mathrm{G}$, short for fourth generation, is the fourth generation of mobile telecommunications technology, Succeeding $3 \mathrm{G}$ and preceding $5 \mathrm{G}$. A $4 \mathrm{G}$ system, in addition to the usual voice and other services of $3 \mathrm{G}$, provides mobile broadband Internet access, and over some networks voice services (known as VoLTE). Potential and current applications include amended mobile web access, IP telephony, gaming services, high-definition mobile TV, video conferencing, 3D television, and cloud computing.

The market is changing. Governments and Health Management organizations are placing greater emphasis, and greater resources, on technology as an improvement tool.

The adoption of technological evolutions in the healthcare, e-governance, education, financial inclusion, Safety \& Security \& Smart City industry faces a number of obstacles due to non availability of good and reliable internet bandwidth. Limited funding allocation for ICT projects and a lack of sufficient financial incentives to encourage technology adoption has often meant inadequate solutions.

4G will have the potential in India:-

[1] Larger broadband coverage, as India suffers from good wired connections.

[2] Better speed and file transfer capability will allow rapid workplace set-up even in remote locations.

[3] Rich machine to machine and remote monitoring applications

[4] Videoconferencing, tele-presence and rich media collaboration \& e-education

[5] Remote access to business applications

[6] Reduce healthcare costs by allowing clinical staff to remotely work together and instantly access patient data.

[7] Serve a growing population of patients with chronic illnesses by allowing physicians to remotely monitor the patient's long - term health.

[8] Improve diagnoses by bringing together data from disparate devices (e.g. monitors, images, therapeutic devices) over time to form a complete picture of a single patient's health status.

The above will be further discussed in details with regard to the digital India initiatives by the government and how the technology will help some of the issues.

\section{Digital India Programme}

Digital India is an ambitious programme of Government of India projected at Rs 1,13,000 crores. This will be for preparing the India for the knowledge based transformation and delivering good governance to citizens by synchronized and co-ordinated engagement with both Central Government and State Government.

This programme has been envisaged by Department of Electronics and Information Technology (DeitY) and will impact ministry of communications \& IT, ministry of rural development, ministry of human resource development, ministry of health and others. This programme will also benefit all states and union territories. The existing/ ongoing e-Governance initiatives would be revamped to align them with the principles of Digital India. The vision of Digital India is to transform the country into a digitally empowered society and knowledge economy. It would ensure that government services are available to citizens electronically. It would also bring in public accountability through mandated delivery of government's services electronically.

The Digital India vision provides the intensified impetus for further momentum and progress for e-Governance and would promote inclusive growth that covers electronic services, products, devices, manufacturing and job opportunities.

Digital infrastructure will focus on providing high speed secure Internet. Governance and services on demand will stress on integrating services across departments and 


\section{International Journal of Science and Research (IJSR) \\ ISSN (Online): 2319-7064 \\ Index Copernicus Value (2013): 6.14 | Impact Factor (2014): 5.611}

jurisdictions and making services available in real time for both online and mobile platform.

Digital empowerment of citizens will pay emphasis on universal digital literacy and availability of digital resources/services in Indian languages.

The programme will be implemented in phases from 2014 till 2018. The source of funding for most of the eGovernance projects at present is through budgetary provisions of respective ministries/departments in the central or state governments. Requirements of funds for individual project(s) for Digital India will be worked out by respective nodal ministries/departments but according to government estimate it will cost Rs 113,000 crore. To implement this the government is planning to strengthen National Informatics Center (NIC) by restructuring it to support all central government departments and state governments. Positions of chief information officers (CIO) would be created in at least 10 key ministries so that e-Governance projects could be designed, developed and implemented faster.

Apart from this, the DeitY would create four senior positions within the department for managing the programme say additional secretary, Digital India; joint secretary, infrastructure development; joint secretary, capacity building and digital enablement; and joint secretary, IT applications in uncovered areas $\&$ process re-engineering

In order to transform the entire ecosystem of public services through the use of information technology, the government of India has approved the Đigital India - Programme with the vision to transform India into a digitally empowered society and knowledge economy.

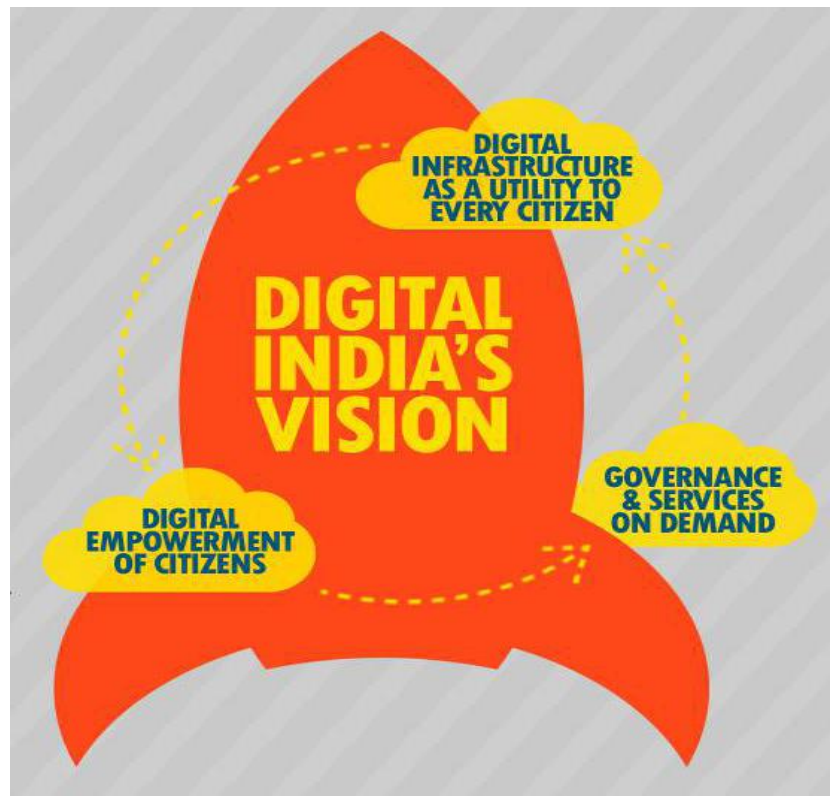

Figure 3: Digital India Initiative

\subsection{Infrastructure as a Utility to Every Citizen}

High speed internet shall be made available in all gram panchayats; Cradle to grave digital identity; Mobile and Bank account would enable participation in digital and financial space at individual level; Easy access to common service centre within their locality; Shareable private space on a public cloud; and Safe and secure cyber space in the country.

\subsection{Governance and Services on Demand}

Single window access to all persons by seamlessly integrating departments or jurisdictions; availability of government services in online and mobile platforms; All citizen entitlements to be available on the Cloud to ensure easy access; Government services to be digitally transformed for improving ease of doing business; Making financial transactions above a threshold, electronic and cashless; and Leveraging GIS for decision support systems and development.

\subsection{Digital Empowerment of Citizens}

Universal digital literacy; All digital resources universally accessible; All government documents/certificates to be available on the Cloud; Availability of digital resources/services in Indian languages; Collaborative digital platforms for participative governance; Portability of all entitlements for individuals through the cloud.

\section{Forth Generation (4G) Technology for Rural Reforms}

Wireless mobile has been increasingly recognized as service of general economic interest in recent years. Wireless Broadband like $4 \mathrm{~g}$ is not just an Technology infrastructure, it's a general purpose technology that can fundamentally change and re structure the economy. Thus, examining the overall economic impact is a logical way to assess the implications of broadband diffusion because it takes a more comprehensive view than looking only at impacts on individuals, firms, or communities. Some of these studies have found a positive relationship between broadband access and economic development, most of them have been restricted to developed economies and their firms and communities, and to qualitative arguments and case studies.

In order to transform the entire ecosystem of public services through the use of information technology, the government of India has approved the - Đigital India - Programme with the vision to transform India into a digitally empowered society and knowledge economy.

However the linkage between a high speed wireless broad band technologies and rural reforms is further more interesting, specifically due to the government focus on digital initiatives.

The Indian government has now set up the target of delivering vast majority of services electronically. The Digital India vision provides the intensified impetus for further momentum and progress for e-Governance and would promote inclusive growth.

Digital infrastructure will focus on providing high speed secure Internet. Governance and services on demand will stress on integrating services across departments and 


\section{International Journal of Science and Research (IJSR) \\ ISSN (Online): 2319-7064 \\ Index Copernicus Value (2013): 6.14 | Impact Factor (2014): 5.611}

jurisdictions and making services available in real time for both online and mobile platform.

\subsection{Forth Generation (4G) Technology for improved out- of-hospital care \& monitoring \& M2M}

The healthcare industry relies on an endless variety of medical devices to assess patient wellbeing - weight scales, thermometers, blood pressure devices, heart rate monitors, glucometers and oxygen monitors just to name a few. These devices work as individual units, measuring only one aspect of patient health and caregivers piece together data to get a complete picture of overall health. Modern healthcare IT systems have improved and simplified this task by aggregating, visualizing and managing patient data on webbased medical platforms. 4G technology and the expanding Internet of Things (IoT) are taking this one step further by leveraging mobile technology and enabling devices to automatically send real time data to back end IT systems via wireless networks. Better speed and file transfer capability will allow rapid set-up even in remote locations, large amount of data will be transferred within few seconds and will be possible to access information's across locations.

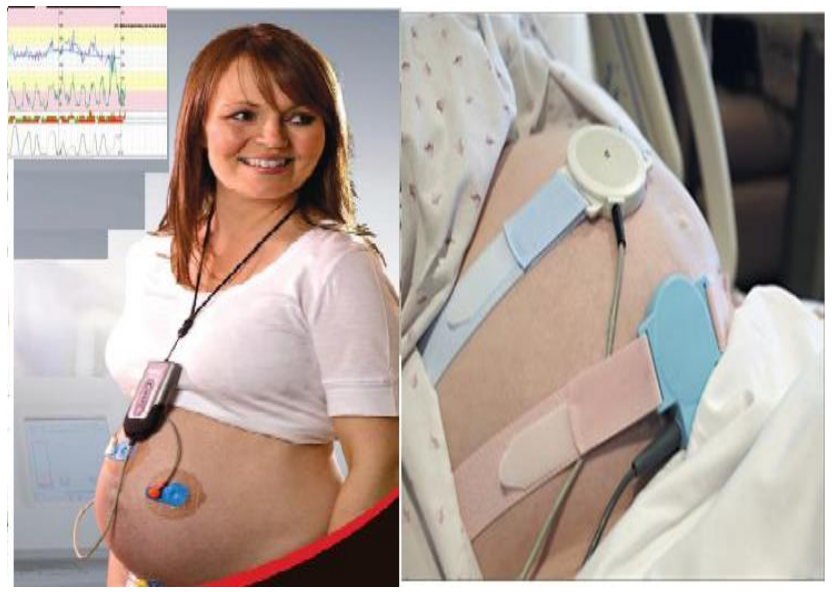

Figure 4: Next Generation Pregnancy Care solutions

Remote patient monitoring and telehealth applications are changing healthcare. For many conditions, healthcare provider office visits are being replaced by home monitoring, thanks to wireless technologies.

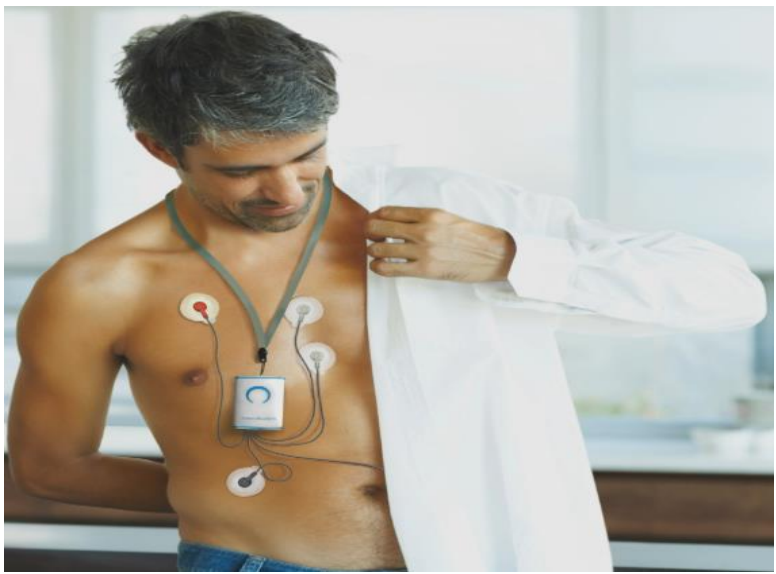

Figure 5: Post Intervention Cardiac care solutions
The technology market intelligence firm ABI Research agrees and predicts that by 2017 , there will be nearly 170 million health and fitness wearable wireless devices worldwide on the market, more than half of which will be specifically designed to improve healthcare through home and remote patient monitoring. Although the remote patient monitoring market still must resolve questions about potential privacy and security issues, the immense demand for quality care coupled with patients' willingness to connect to real-time network communication systems will drive major growth in the years to come.

According to Gartner, through 2017, annual spending on medical informatics needed for EHR optimization will trend toward five times the initial informatics costs.

4G has been marketed by Telecom operators as a highspeed / low-latency service, but the network has far more bandwidth than most M2M applications need. However, these new networks use OFDM (orthogonal frequencydivision multiplexing), a method of digital modulation in which a signals are split into several narrow band channels having different frequencies. This allows bandwidth to be assigned in a very flexible way and in turn this will allow operators to offer cost-effective, low-bit rate services for use in M2M solutions.

In addition, LTE networks are significantly more efficient than those of earlier generations. They are based on a simplified, flat, all-IP architecture having open interfaces and an evolved packet core. This will result in a global infrastructure that can accommodate more than 10 times and will facilitate the deployment of tens of billions of smart devices that are predicted for the Connected World. . 4G will offer higher bandwidth and low latency and will therefore make more sense for applications like M2M which requires constant touch and mass distributions.

\subsection{Improving the Quality of Primary Education}

India educational system is the second largest in the world. A national survey has revealed that almost $230 \mathrm{Mn}$ children are studying in 13 lakh schools across the country. Figures released by the Indian government in 2011 show that there were 58,16,673 elementary school teachers in India. As of March 2012 there were 21,27,000 secondary school teachers in India.

However, one-fifth of the total primary schools in rural areas still do not have drinking water facility. The gap between the planned and the realized goals of education continues be so large that even the basis of educational planning and underlying assumptions can be easily challenged. The basic educational planning models have gone off the trajectory both at the central as well in the states.

The National Policy on Education (NPE), and the revised NPE reiterated the urgency to address the quality concerns in schools education on priority basis. Quality can not improve by itself. It requires reforms in teacher training; improvements in the facilities and infrastructure in schools, motivation level of teachers and a most importantly change in the style of teaching to make it attractive to the students. 


\section{International Journal of Science and Research (IJSR) \\ ISSN (Online): 2319-7064}

Index Copernicus Value (2013): 6.14 | Impact Factor (2014): 5.611

In actual practice, there has always been a trade-off between quality and quantity, in favor of the latter. This not only affected the internal efficiency of the educational system but also resulted in a situation where only a few graduates of the school and higher education system could attain the expected skills and competencies.

With lower data transmission and hardware costs make it is possible to add $4 \mathrm{G}$ technology chip sets to smaller-scale products which can help in improving the quality of education.

4G technology can offer higher speed and with the help of $4 \mathrm{G}$ rural broadband will be a reality, as India suffers from good wired connections. Better speed and file transfer capability will allow rapid class room set-up even in remote locations. It will also help in accessing the similar quality of contact across the locations and will facilitate quality education across the locations.

Since the schools will be in the fixed location and will be able to get up to 16-32 mbps of practical speed, which will allow schools to stream video's almost in real time. 4G will offer higher bandwidth and low latency and will therefore make more sense for applications which requires constant touch and faster bandwidth.

\subsection{G as backbone to Digital India Programme}

Digital India as a very ambitious program of government of India and will play a very important role in the rural reform. Very first part of the digital India program is the digital infrastructure in every Gram panchayats. The Success of programme is completely dependent on the availability of good Infrastructure as a utility to every citizen.

Government of India started USOF project to enable rural broadband and this project was awarded tot the government owned Bharat Sanchar Nigam Limited(BSNL). Out of the total $8,88,832$ broadband connections to be provided under the project, BSNL provided 6, 56,354 connections till Jan 2015 in the rural India. However, more than $50 \%$ of connections were never even been used due to many technical or usability challenges.

4G can provide High speed internet and which can be made available in all gram panchayats, post offices and to Common Service Centers. 4G can offer fast and secure access to private space on a public cloud, and accelerate the development of application for e/m-governance.

E-governance can be further improved by improving the management of information and access to that information, including

- Management of logistics of patient care

- Administrative systems

- Patient records

- Land records

- Biomedical literature search and retrieval

- Continuing professional development of health workers

- Telemedicine and remote diagnostic support

- Diagnostic imaging
- Critical decision support systems

- Quality assurance systems

- Disease surveillance and epidemiology

- Rural and woman Safety, security \& Surveillance

\section{Conclusions}

The market is changing and technology is playing an important role in the transformation. In order to transform the entire ecosystem of public services through the use of information technology, the government of India has approved the Đigital India - Pogramme with the vision to transform India into a digitally empowered society and knowledge economy. Governments and Health Management organizations are placing greater emphasis, and greater resources, on technology as an improvement tool.

The adoption of technological evolutions and adoption in the healthcare, e-governance, education, financial inclusion, Safety \& Security, Smart City Initiatives etc faces a number of obstacles due to non availability of good and reliable internet bandwidth. Reliable and fast internet is still a dream in the rural India.

4G as a technology is very powerful and will be capable of providing between $100 \mathrm{Mbit} / \mathrm{s}$ and $1 \mathrm{Gbit} / \mathrm{s}$ speeds both indoors and outdoors, with premium quality and high security. Depart of Telecom(DOT) has already awarded BWA(4G) license and few operators are offering $4 \mathrm{G}$ services in a very limited manner.

Limited funding allocation for ICT projects and a lack of sufficient financial incentives to encourage technology adoption has often meant inadequate technological impact.

\section{References}

[1] eHealth Tools and Services. Needs of the Member States. Report of the Global Observatory for eHealth, WHO 2006

[2] A Best Practises White Paper; Presented by Rocket Builders, Based on Research Co-Funded by the National Research Council of Canada, Industry Canada and Rocket Builders; - Capitalizing on the Opportunity"

[3] Improving Health, Connecting People: The Role of ICTs in the Health Sector of Developing Countries" , A Framework Paper, Edited by Andrew Chetley; with contributions by Jackie Davies, Bernard Trude, Harry McConnell, Roberto Ramirez, T Shields, Peter Drury, J Kumekawa, J Louw, G Fereday, Caroline NyamaiKisia.

[4] Department of Electronics \& IT (Deity), Ministry of communication \& IT, Govt. of India. http://deity.gov.in/sites/upload_files/dit/files/Digital $\% 2$ OIndia.pdf

[5] A User-centered Approach to Healthcare ICT Development, Licentiate's Thesis, Johanna Viitanen, HELSINKI UNIVERSITY OF TECHNOLOGY, Department of Computer Science and Engineering

[6] Information and Communication Technology (ICT) is Transforming Healthcare Education in the Philippines", 


\section{International Journal of Science and Research (IJSR) \\ ISSN (Online): 2319-7064}

Index Copernicus Value (2013): 6.14 | Impact Factor (2014): 5.611

WHITE PAPER, Transforming Medical Education Through ICT, Intel World Ahead Program

[7] - Gallenges and Prospects of E-governance in Education" by Sudip Suklabaidya1, Angshu Maan Sen (International Journal of Emerging Trends \& Technology in Computer Science (IJETTCS))

[8] ICT Application in Health - Developing Methods towards Skill development of Healthcare Providers, N. Vijayaditya, Director General, National Informatics Centre, New Delhi, India

[9] Economic Impacts on Broadband by Christine ZhenWei Qiang and Carlo M. Rossotto with Kaoru Kimura

[10] Digital India Programme online content http://www. digitalindia.gov.in/

[11] Quality Concerns in Primary Education in India. Yash Aggarwal, NIEPA

[12] ITU-T Recommendations and other Publications online on LTE-A, 4G and LTE http://www.itu.int/en/ITUR/Pages/default.aspx

\section{Author Profile}

Uttam Kumar received the B.Tech degree in computer science from University of British Columbia, Canada and holds Post Graduate Diploma in IT \& Management from All India Management Association, New Delhi, India.. in 1999 and 2004, respectively. He has also completed B.A in Economics and Masters Degree in Human Resource and Management. He is a certified Project Management Professional (PMP) from Project Management Institute and is working in the practicing. He is doing research in the field of management from DR. K.N Modi University, Rajasthan, India 